\title{
Aflatoxicosis Associated with Swine Stillbirth in the Piggery Farm University of Agriculture Makurdi
}

\author{
Jatfa JW' ${ }^{1 *}$, Wachida $\mathrm{NM}^{2}$, Ijabo $\mathrm{HM}^{3}$ and Adamu $\mathrm{SS}^{4}$ \\ ${ }^{1}$ Department of Veterinary Medicine, College of Veterinary Medicine, University of Agriculture, Nigeria \\ ${ }^{2,3}$ Department of Veterinary Surgery and Theriogenology, University of Agriculture, Nigeria \\ ${ }^{4}$ Veterinary Teaching Hospital University of Agriculture, Nigeria
}

Submission: February 17, 2018; Published: April 12, 2018

*Corresponding author: Jatfa JW, Department of Veterinary Medicine, College of Veterinary Medicine, University of Agriculture, P.M.B. 2373,Makurdi, Nigeria, Tel: +2348068040974; Email: jatfaw@gmail.com

\begin{abstract}
Stillbirth in pigs can be define as piglets born dead or dies shortly before or during parturition. The occurrence is worldwide and the effect is significant if greater than $7 \%$ piglets born dead. This study investigated two cases of multiparous large white sows, the first was a case of four (4) stillbirth and the second thirteen (13) dead fully developed piglets within the interval of one week. The cultured feed sample on Sabouraud Dextrose Agar (SDA) indicated Aspergillus flavus growth while the mycotoxin analysis and quantification of the feed samples were positive to aflatoxin at the level of $80 \mathrm{ppb}, 90 \mathrm{ppb}$ and $110 \mathrm{ppb}$ concentration. In conclusion, it is established that the feed material are contaminated with aflatoxin of harmful concentration and should have been responsible for the still born piglets.
\end{abstract}

Keywords: Stillbirth; Piglets; Aflatoxin; Sows

\section{Introduction}

Stillbirth in swine can be defined as birth in which a piglet is born dead or dies shortly before or during parturition. The occurrence is worldwide and the effect is significant if greater than $7 \%$ piglets born dead [1]. Several risk factor are associated with stillbirth, about $70 \%$ are related to factors including: genotype, nutritional deficiency, environmental stress, dystocia, hypoxia, poison and age [2]. The remaining 30\% are associated with infectious agents and these may be responsible for notable diseases including Mycoplasma suis, PRRS arcovirus, leptospirosis and mycotoxicosis [3,4].

The factors mentioned above may result in reproductive failure in a pregnant sow leading to a broad spectrum of sequaelae characterized by abortion, stillbirth infertility, mummification and embryonic death [1]. For example, mycotoxins, the biochemical metabolite of fungi and the possibility of feed contamination may result in both man and animal mycotoxicosis. Scientists have identified a few out of large numbers of fungi (Aspergillus flavus A. parasiteus, A. nominus), that are capable of germinating and producing mycotoxins in grain at 15\%-17\%-moisture of content when contaminated [5]. Above 400 mycotoxins are known to date, but only a few have been shown to cause significant, detrimental health and performance problems in swine fed with contaminated plant based feedstuffs. These include aflatoxin, deoxynivalenol, zearalenone, fumonisin, ochratoxin, ergot, and T-2 toxin [5]. Aflatoxin toxicosis has been severely reported in suckling piglet, growing and finished and breeding pigs. However, the risks of aflatoxin contaminated feeds depend largely on the age and physiologic status of animal as well as the level of toxin in the feed [6]. This study report two cases of multiparous large white sows, the first was a case of four (4) stillbirth and the second thirteen (13) fully developed piglets in the same university farm within the interval of one week.

\section{Case History}

The attention of the ambulatory unit Veterinary Teaching Hospital University of Agriculture Makurdi (UAM), was draw to the piggery section of the Animal Farm UAM, with chief complain that one of the sow has decrease appetite with eventual farrowing dead piglets, however, records of the sow farrowing history reveals: first farrow 18-piglets, second farrow 9-piglets were successful but the third farrow resulted in 13-dead fully matured piglets. Further history also reveals that the sow was raise under intensive management system. The farm records indicated that, they were routinely treated for endo and ecto parasite and was fed with breeder ration locally compounded basically with (soyabeans, rice bran, brewer dry gin, premix zinc oxide and bone meal). The feed store investigation reveals moldy contaminated feed materials in large quantities, which are used as the main source of feeding the sow. Therefore, it became apparent to incriminate microbial contamination (Table 1). 
Table 1: showing the quantification of the aflatoxins in the sample of feeds. ELISA Reading at 450nm optical Density (OD), (Helica Biosystem Inc.Santa Ana CA).

\begin{tabular}{|c|c|c|c|c|}
\hline Feed Sample (15kg) & Total Aflatoxin (bbp) & Optical Density (OD) & $\begin{array}{c}\text { Maximum permissible } \\
\text { level (bbp) }\end{array}$ & Commendation \\
\cline { 1 - 4 } A & 80 & $450 \mathrm{~nm}$ & 20 & \multirow{2}{*}{ Higher than the standard } \\
\hline B & 90 & $450 \mathrm{~nm}$ & 20 & \\
\hline C & 110 & $450 \mathrm{~nm}$ & 20 & \\
\hline
\end{tabular}

\section{Physical, clinical and necropsy examination}

The 31/2 year old large white sow was apparently health with no sign of disease, weighting $150 \mathrm{~kg}$, rectal temperature was $38.4{ }^{\circ} \mathrm{C}$, stable in appearance but scaly skin characterized with papillomatous like growth at the base of the ear.

\section{Necropsy of the dead piglets}

At necropsy, observation of the dead piglets lungs were not expanded indicating that they died breathing; the gastrointestinal tract contained no ingesta and appeared apparently healthy.

\section{Laboratory test}

Serum sample from the sow was collected for Brucella Rose Bengal immune-diagnosis. And the sow vaginal swab together with the dead piglets thoracic fluid were collected for culture and sensitivity test, which was carried out at the Veterinary Teaching Hospital (VTH) University of Agriculture Makurdi. While the moldy feed sample was collected and cultured in the Veterinary Microbiology Laboratory, UAM and part of the same sample was send for bio-assay at the Disease Diagnostic and Control Laboratory, Animal Care Service Konsult Lagos Nigeria.

\section{Result}

The Rose Bengal immunologic test yielded negative as well as the cultured results of the sow vaginal swab and thoracic fluid from the death piglets. However, the cultured feed sample on Sabouraud Dextrose Agar (SDA) indicated Aspergillus flavus growth within two weeks. While the mycotoxin analysis and quantification was carried out using Enzyme Link Immuonsorbent Assay (ELISA) technique and read at $450 \mathrm{~nm}$ (Helica Biosystem Inc.Santa Ana. CA). The reading at $450 \mathrm{~nm}$ optical Density (OD), of the three (3) samples of $15 \mathrm{~g}$ each from three separates bags were positive to aflatoxin at the level of $80 \mathrm{ppb}, 90 \mathrm{ppb}$ and $110 \mathrm{ppb}$. The values are above the normal permissible level of $20 \mathrm{ppb}$ aflatoxin in feed. The conditioned was therefore diagnosed as aflatoxicosis and this was consistent with the history of recent feeding from a new bag of food and sign of altered food palatability.

\section{Discussion and Conclusion}

In the case of this study the dead piglets lungs were not expanded at necropsy indicating that they died not breathing (intrapartum); This finding agreed with Vaillancourt et al. [7], which reported that majority of stillborn piglets die intrapartum i.e sometimes during the farrowing process which is usually characterized by non-expansion of the lungs following a postmortem finding. But early postpartum deaths are those that occur within 24 hours after birth. Unless a necropsy is performed, it is often difficult to differentiate intra and postpartum death.

Aflatoxicosis have been severally and frequently reported in suckling pig, grower and breeding stock but this is the first report from the UAM Animal Farm. Swine appear resistance to the concentration of $300 \mathrm{ppb}$ from weaning to market [8] and high concentration of about $1000-5000 \mathrm{ppb}$ was reported to precipitate acute condition and death. However, Marin et al. [9] stated that a low level of $20-200 \mathrm{ppb}$ is capable of eliciting immune suppression; increase susceptibility of microbial infection especially pregnant sows being the most susceptible to the toxic effect of aflatoxin. And this is in agreement with the aflatoxin concentration of $80 \mathrm{ppb}, 90 \mathrm{ppb}$ and $110 \mathrm{ppb}$ respectively in this study. Nevertheless, there is variability in clinical signs of acute aflatoxicosis, for example, in a reported outbreak involving at least 100 dogs fed on commercially manufactured food, following the dogs examinations, only eight (8) were confirmed with aflatoxicosis [10].

Aflatoxins are not only potent toxins but also are carcinogenic, mutagenic and immunosuppressive. Therefore, this might explain the reason for the pregnant sow leading to still birth. The attendant impact or effect of aflatoxicosis includes reduce productivity, increase disease incidence and reproductive abnormalities in pigs for example stillbirth [11]. Therefore, this constitute a major source of economic loss for the producer, for example, the financial consequence of increase stillbirth level in a farm can be reasonably high; exceeding the 5-7\% intervention level, a three hundred (300) sows breeding herd experiencing a $10 \%$ stillbirth, this will signify a loss of 235 piglets per year. And if each of these stillbirth piglets were to be fully prized within a breeder feeder enterprise this represent a financial loss of over $\$ 350,000$ per year [12].

\section{Conclusion and Recommendation}

Based on the clinical/postmortem signs, the growth of Aspergillus flavus on growth culture medium and the bio assay detection of aflatoxin; It is established that the feed material are contaminated with aflatoxin of harmful concentration and should have been responsible for the still born piglets, therefore preventive measures to reduce stillbirth piglets are necessary, such as farrowing supervision and timely intervention. Also, emphasis on analysis of stored feeds to avoid moldy growths should always be a routine in the farm. 


\section{References}

1. Cutler RS, Fahy VA, and Spicer EM (1992) Preweaning mortality. In Leman AD S Taylor (Eds) Disease of Swine (7th edn.), wolf, pp. 847-860

2. Vanderhaeghea C, Dewulf J, de Kruifb, Maes D (2013) Non-infectious factors associated with stillbirth in pigs: A review. Animal Reproduction Science Volume 139(1-4): 76-88.

3. Borges VF, Bernardi Mc, Bortolozzo FP, Wentz I (2005) Risk factor for still birth and fetal mummification in four Brazillian Swine Herds Preventive Vet Med.

4. Gugjoo MB, Ahmad RA, Bhat SA, Wani MY (2012) Stilbirth in pigs. Journal of Advanced Veterinary Research 2(3): 218-231.

5. Cranshaw M (2008) Many Non-infectious factors associated with stillbirth in pigs: A review Mycotoxin in Swine Diets.

6. Prelusky DB, Rotter BA, Rotter RG (1994b) Toxicology of mycotoxin. In: JD Miller and HL Trenholm (Eds) Mycotoxin in grains compound other than Aflatoxin Eagar Press St Paul Minnesota, pp. 359-403.
7. Vaillancourt JP, Marsh WE, Dial GD (1994) Perinatal mortality in 48 North American Swine herds, Swine Health and production 2(3): 13

8. Moneque, HJ, CE Combs GT, Wallace HD (1977) The effect of various levels of Aflatoxins on young swine. Florida Agriculture Experiment Station Reports AL.

9. Marin DE, Taranu I, Bunaciu RP, Pascale F, et al. (2002) Change in performance, blood parameters, humoral and cellular immune response in weanng piglet exposed to low doeses of Aflatoxin. journal of Animal Science 80: 1250-1257.

10. Katherine AS, Joanne RS, Shelly JN, Leslie BN (2006) Aflatoxicosis in dogs and dealing with suspected contaminated commercial foods, Timely topics nutrition JAVMA 228(11): 1686-1691.

11. Hannes V (2008) Mycotoxins- Overview and effects in Pigs. AFGRI Animal Feeds.

12. www.nadis .org.uk

Your next submission with Juniper Publishers will reach you the below assets

- Quality Editorial service

- Swift Peer Review

- Reprints availability

- E-prints Service

- Manuscript Podcast for convenient understanding

- Global attainment for your research

- Manuscript accessibility in different formats ( Pdf, E-pub, Full Text, Audio)

- Unceasing customer service

Track the below URL for one-step submission https://juniperpublishers.com/online-submission.php 